

Director: Per Stangeland

Coordinadora: Ma José Garrido de los Santos Publicado por la Sección de Málaga del IAIC Facultad de Derecho, Universidad de Málaga Campus de Teatinos, 29071 MALAGA Tel:(95) 2132325 - Fax:(95) 2132242 Depósitolegal:MA857/1996ISSN:1137-2427 Internet: Http://www.gen.com/emn/crimi http://www.emn.derecho.uma.es/crimi

La Sección de Málaga del IAIC presenta en este número del Boletín criminológico diversa información sobre la evolución de la docencia del título de Experto universitario en Criminología. Entre los datos aportados sobre la evolución del alumnado en los últimos cinco años destacaría la consolidación del interés en estos estudios, con un número estable entre 230 y 240 matriculados, y la persistencia de la pluralidad del origen académico y profesional de los alumnos, que mantiene vivo el espíritu de interdisciplinariedad de la Criminología.

Por lo que se refiere a la valoración de los estudios por parte de los egresados, resulta especialmente significativo que ya en los dos primeros años de impartición de estos estudios, ámbito temporal al que ha debido limitarse la encuesta, se obtenga una valoración global de notable alto, que confiamos haber ya superado en estos últimos años una vez solventados los problemas iniciales de adaptación del profesorado y de adecuada configuración de aquellas asignaturas más ajenas a la formación original del alumnado. Interesante resulta igualmente resaltar que las propuestas de introducción, reducción o ampliación de materias o de mayor atención a las prácticas ya han sido tenidas en cuenta en el nuevo plan de estudios que se está impartiendo desde el curso 96-97. Finalmente resulta satisfactorio comprobar el alto porcentaje de titulados que han sacado o esperan sacar rendimiento a la titulación en su promoción profesional, así como el continuado interés por seguir participando en actividades formativas del Instituto.

José Luis DÍez Ripollés Director de la Sección de Málaga del I.A.I.C

\title{
Instituto de Criminología: 5 años de docencia
}

El Instituto Andaluz Inter- universitario de Criminología es un centro universitario de investigación científica y técnica, así como de especialización, creado por Decreto de la Junta de Andalucía 182/1990, de 5 de junio, al amparo de las posibilidades ofrecidas por el art. 10 de la Ley de Reforma Universitaria.

Ell I.A.I.C. desarrolla sus actividades en el campo de las disciplinas psicológicas, sociológicas, médicas, penales, penitenciarias, criminológicas y político-criminales. Para ello ha conseguido aunar en un único centro de investigación y especialización todos los recursos humanos y materiales de las respectivas áreas de conoci- miento de cinco Universidades andaluzas, entre ellas la de Málaga, desde donde se elabora el Boletín Criminológico.

Entre los fines del I.A.I.C. está el organizar, programar y desarrollar enseñanzas especial izadas del conjunto de las disciplinas antes mencionadas. Con este propósito la Universidad de Málaga a través de la Sección de Málaga del I.A.I.C. viene ofertando el Título de Experto Universitario en Criminología, ayyo plan de estudios se desarrolla durante 3 cursos académicos (780 horas) y va dirigido a universitarios que han superado el primer ciclo de estudios en aulquier carrera universitaria, así como a determinados profesiona-

\section{AUTOR:}

Angel Serrano García

les especialmente relacionados con estos temas siempre que tengan superado el examen de acceso a la Universidad (cuerpos y fuerzas de seguridad del Estado, investigadbres privados, etc.) .

Ell presente estudio, ciranscrito a la Sección de Málaga, tiene una dbble finalidad: mostrar la evolución del número de alumnos que han cursado estudios durante el quinquenio de existencia del Instituto, así como su perfil y, por otro ladb, reflejar los resultadbs de una encuesta realizada a las dos primeras promociones de alumnos que obtuvieron la Titulación de Experto Universitario en Criminología.

\section{Boletín \\ Criminológico \\ $N^{o} 30 \quad$ Septiembre 1997 \\ Página




\section{Metodología}

Durante el mes de julio de 1997 se remite a los domicilios de los alumnos de las dos primeras promociones de titulados en Criminología un cuestionario totalmente anónimo con 23 preguntas sobre diversas cuestiones relacionadas con la valoración y crítica de la titulación, la posible organización de actividades dirigidas a los postgraduados en Criminología, y sobre la utilidad de los estudios realizados y su posible adecuación al mundo laboral del alumno.

El tamaño de la población estudiada, 97 alumnos, corresponde a los que han finalizado la titulación en Málaga durante los cursos académicos 94/95 y 95/96, es decir, los alumnos que están en condiciones de ofrecer unas respuestas más cualitativas al conocer la titulación en su conjunto y poder poner en práctica los conocimientos adquiridos. La tasa de respuesta, cuestionarios cumplimentados y remitidos al Instituto, representa un $56,7 \%$ (55 alumnos) del conjunto de la población y es el marco donde se ha desarrollado el presente estudio.

Todos los datos estadísticos relativos a la evolución del número de alumnos y su perfil han sido obtenidos de los ficheros que obran en la secretaría de Málaga del I.A.I.C.

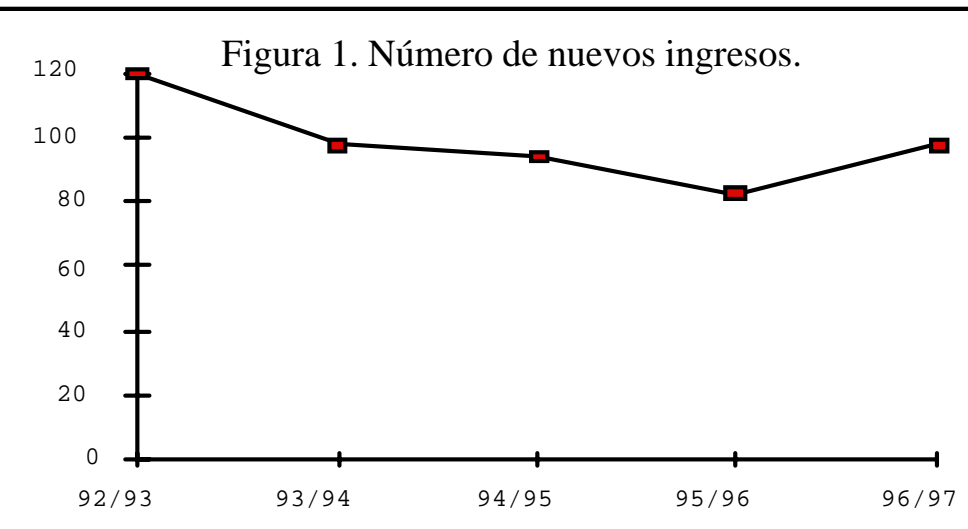

Evolución del número de alumnos y su perfil

\section{A. Evolución}

La dbcencia de la Titulación de Experto Universitario en Criminología se inició durante elarso académico 1992/93, estableciéndose un cupo máximo de120 alumnos para el primer curso. Dada la expectativa existente en Málaga se logró cubrir el cupo sobradamente. Posteriormente durante los años 93/94 y 94/95 la Titulación quedó completamente implantada con el segundo y tercer curso respectivamente.

La evolución desde el iniciode la Titulación, analizada a partir del número, en téminos absolutos, de alumnos que acceden a los estudios de Criminología por primera vez (nuevos ingresos) y del total de alumnos de los tres arsos en que se estructura la Titulación de Experto, es el objeto de esteprimer apartado.

Como se ha comentando anteriomente, durante el curso 92/93 (inicio de la actividad dbcente de la titulación) el número de nue-



vos ingresos fue de 120 lo que representó el 100\% de las plazas ofertadas. Durante los cuatro años siguientes se consolida la titulación con unos niveles de nuevos ingresos en tomo a los 100 alumnos que, comparativamente, colocan a la Sección de Málaga en el primer nivel entre las cinco Universidades andaluzas donde el título se imparte. En la figura número 1 se observa claramente el proceso de consolidación.

Por otro lado el número total de alumos, considerado a partir de la suma de los tres cursos en que se estructura la titulación, ha experimentado igualmente un proceso de consolidación que hace prever a partir del curso próximo (1997/98) un aumento, potenciado por los nuevos ingresos. En la figura número 2 se observa la evolución (hay que tener en cuenta que durante 1992/93 sólo se impartía docencia de primer aurso, y durante 1993/94 de primero y segundo, por lo que en los dos primeros años de la titulación el número total de alumnos estaba depreciado por la falta de un arrso) .

\section{B. Perfil del alumno}

La distribución por sexos, siguiendo la tónica general de las demás titulaciones universitarias, da lugar a una presencia mayoritariamente femenina. En términos porcentuales y tomando como valor el número total de alumnos que se han matriculado en la titulación descle su creación, un

\section{$\begin{array}{llllllll}\text { Boletín Criminológico } & N^{o} & 30 & \text { Septiembre } & 1997 & \text { Página } & 2\end{array}$}


52\% corresponde a alumnas y un 48\% corresponde a alumnos. Conviene comparar estas cifras, que representan los últimos cinco años en conjunto, con el curso 96/97 en el que el ingreso de alumnas fue significativamente mayor: un 59\% frente a un 41 \% respectivamente.

Respecto a la distribución por sexos de los alumnos que están en posesión de la titulación, un 54\% es masculino frente a un 46\% femenino. Es importante aclarar que estas cifras corresponden a las dos únicas promociones de la titulación que finalizaron sus estudios en 1995 y 1996 y que por lo tanto ingresaron en el Instituto en los arsos 92/ 93 y 93/94 respectivamente, periodo durante el cual la distribución por sexos era prácticamente igual.

La procedencia (considerada como la titulación o situación profesional desde donde se accede) es muy variada y hetereógenea; sin embargo desde el inicio de las actividades docentes del Instituto, la Facultad de Derecho ha sido y es la principal fuente de origen de los alumnos que se matriajlan.

Del análisis de la figura número 3 podemos doservar que las seis fuentes principales de procedencia de alumnos durante los cincos

Figura 4. Ambito de desarrollo profesional de los titulados.

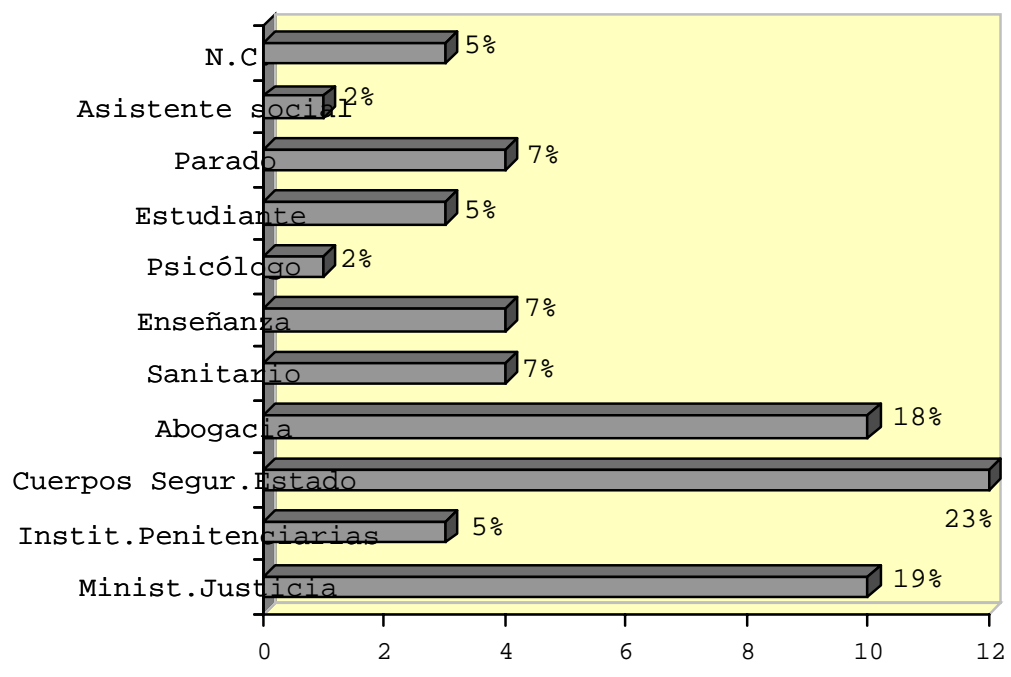
con 23 alumnos (5\%) . sitúa en tomo a los 28 años.
Figura 3. Procedencia de los alumnos



cursos académicos de existencia de la docencia en el Instituto son: $1^{\circ}$. - Licenciado o Diplomado en Derecho con 182 alumnos (37\%); $2^{\circ}$ Licenciado o Diplomado en Psicología con 55 alumnos (11\%); $3^{\circ}$ Funcionarios de Justicia e interior con 38 alumnos (8\%); 4 Diplomado en Trabajo Social con 36 alumnos (7\%); 5 Policía Local con 30 alumnos (6\%) y $6^{\circ}$ Guardia Civil

En cuanto a la edad media del alumno de Criminología, se

Resultados de la encuesta rea-

\section{A. Nivel de titulación y ámbito de desarrollo profesional}

El actual nivel de titulación oficial de los Expertos en Criminología es como sigue: $1^{\circ}$.- Licenciado en Derecho (40\%); $2^{\circ}$.Selectividad/Acceso (14,5\%); $3^{\circ}$.Licenciado en Psicología (12,7\%); 4. - Diplomado en Trabajo Social $(10,9 \%) ; 5^{\circ}$. - Otras titulaciones $(12,7 \%) ; 6^{\circ}$. - No contesta (9\%) .

Respecto al ámbito donde desarrolla su actividadprofesional, en la figura número 4 podemos observar las profesiones de los titulados en Criminología. Se distinguen tres grandes grupos: Ministerio de Justicia e Interior con un 24\% de los encuestados, Cuerpos de seguridad con un 23 \% y ejercicio libre de la abogacía con un $18 \%$.

A diferencia de otras titulaciones universitarias, el alumno que accede a Criminología desempeña mayoritariamente con anterioridad a su acceso una actividad profesional, lo que aclara dos extremos: el relativobajo índice de paro que declaran los encuestados, 7\%, y que sólo al 7,2\% de los en-

\section{Boletín


cuestadbs el título en Criminología les ha faci litadb la dotención de un puesto de trabajo. Sin embargo, el 11을 reconoce haber obtenido a partir de su nueva titulación un ascenso profesional que cal ifica de importante, y el 25\% cree que a corto/medio plazo consegui rá gracias a los nuevos conocimientos adquiridbs una promoción profesioral.

\section{B. Valoración de la titulación}

Ell contenido de las enseñanzas recibidas y la cal idad didáctica del profesoradb que las impartió les ha merecido a los encuestados la siguiente puntuación (en una escala del 1 al 10) :

\begin{tabular}{|lcc|}
\hline Area & Contenido & $\begin{array}{c}\text { Calidad } \\
\text { profes. }\end{array}$ \\
\hline Jurídica & 8 & 7,9 \\
Criminológica & 5,1 & 4,6 \\
Psicológica & 6,3 & 5,8 \\
Psiquiátrica & 7,3 & 7,1 \\
Sociológica & 7,1 & 7,2 \\
Médica & 8,8 & 9,1 \\
Estadística & 4,6 & 5 \\
\hline
\end{tabular}

Los seminarios impartidos en el Instituto han merecido una valoración de 6,2 puntos. A la pregunta de cuál destacaría como el más interesante y mejor realizado, para un 55\% fue el de Policía Científica, el de Identificación Cadavérica para un 20\% y el de Medicina Legal para un 5,5\%.

La expectativa inicial que tenía el alumno cuando ingresó en el I.A.I.C. ha sidb satisfecha con un grado de puntuación de 6,2 puntos en una escala del 1 al 10, mientras que los conocimientos adquiridos durante sus estudios de Criminología han sidos valorados con 6,9 puntos.

En cuanto a la atención administrativa recibida durante su estancia en el Instituto por el personal de administración y servicios adscrito al I.A.I.C., se valora con 7,5 puntos.

Para finalizar el apartado sobre la titulación, los encuestadbs debían de valorar globalmente su paso por el I.A.I.C., al que califican con 7,6 puntos.

\section{Actividades docentes}

\section{propuestas}

Los encuestados muestran un alto interés porque el Instituto de Criminología realice actividades donde su participación pueda tener cabida. En este apartado vamos a analizar las distintas propuestas realizadas.

A la pregunta de si estaría interesadb en que el título organizara cursos de especial ización para los postgraduados en Criminología sobre distintas materias, un 42\% se muestra muy interesado, un 47\% interesado y sólo un 9\% muestra poco interés. Por otro lado se pide que señale sobre qué materias les gustaría recibir estos cursos especializados; las más destacadas son las siguientes: $1^{\circ}$.Medicina Legal (36\%); $2^{\circ}$.- Jurí-
dica-Criminológica (27\%); $3^{\circ}$.-Policía Científica (22\%); 4. Prevención social de la delincuencia (16\%) ; 50. - Investigación privada (13) ; 60. - Sociología (9\%) ; $7^{\circ}$.Psiquiatría $(9 \%) ; 8^{\circ}$. - Psicología (9\%) .

Igualmente los encuestados muestran su interés en que el I.A.I.C. realice otras actividades donde puedan específicamente intervenir los titulados, destacandb conferencias (27\%), prácticas (24\%), seminarios (22\%), intercambios científicos (16\%), visitas a centros de interés (9\%) e investigación (5\%) .

Por último, se les preguntó qué les gustaría incluiry el iminar en los estudios de Criminología. Dentro de la gran variedad de propuestas, destacamos respecto a lo que debería incluirse: $1^{\circ}$. -Més prácticas (35\%) ; $2^{\circ}$.- Mejorar el profesorado (15\%); $3^{\circ}$.-Convertir la titulación en oficial (11\%); 4․ - Más materia sobre Criminología (5\%). En cuanto a excluir o mejorar: $1^{\circ}$.Excluir Estadística (11\%); $2^{\circ} .-$ Mejorar la participación en clase del alumno (5\%) .

\section{Título de Experto Universitario en Criminología}

El Instituto Andaluz interuniversitario de Criminología de la Universidad de Málaga imparte estudios de Experto Universitario en Criminologia cuya duración es de tres años.

Los interesados deben haber realizado el primer ciclo de estudios universitarios o bien, teniendo probada la selectividad o equivalente, pertenecer a las Fuerzas y Cuerpos de Seguridad del Estado, Guardia Civil, Policía Liocal, Administración de Justicia, Instituciones Penitenciarias o ser trabajador de Seguridad Privada o investigador privado.

Todo tipo de información sobre el contenido y estructura del título y las condiciones de ingreso se puede obtener en la Secretaría del Instituto (Facultad de Derecho de la Universidad de Málaga) teléfono 2132325.

\section{Beca de investigación criminológica}

Se convoca una beca de investigación adscrita al proyecto europeo que coordina la Dra. Rosemary Barberet, Profesora del IAIC de la sección de Sevilla. Para más información, teléfono 2132325.

\section{Boletín Criminológico $\quad N^{o} 30 \quad$ Septiembre $1997 \quad$ Página 4}

